8. Леготкина Л.Р., Лопатина А.Б. Физическая культура как система ценностей // Успехи современной науки. 2016. Т. 2, № 11. С. 46-48.

9. Лубышева Л.И. Концепция физкультурного воспитания: методология развития и технология реализации // Физическая культура. 1996. № 2. С. 11-17.

10. Лубышева Л.И. Современный ценностный потенциал физической культуры и спорта и пути его освоения обществом и личностью // Физическая культура. 1997. № 6. С. 10-15.

11. Пономарева Т.А. Интенционные ценности физической культуры студенческой молодежи // Педагогико-психологические и медико-биологические проблемы физической культуры и спорта. 2017. T. 12, № 1. С. 74-81.

12. Хрусталев Ю.М. От этики до биоэтики. Ростов-на-Дону: Феникс, 2010. 446 с.

13. Шустерман Р. Мыслить через тело: гуманитарное образование // Вопросы философии. 2006. № 6. С. 52-67.

14. Борисов А.Я. Готовность будущего учителя к приобщению школьников к ценностям физической культуры: методика формирования. Самара: ПГСГА, 2016. $108 \mathrm{c}$.

15. Левченко Е.П. Подготовка будущих учителей физической культуры к реализации здоровьесберегающих образовательных технологий. Самара: СГПУ, 2007. $188 \mathrm{c.}$

16. Смирнов Н.К. Здоровьесберегающие образовательные технологии и психология здоровья в школе. М.: АРКТИ, 2005. 320 c.

17. Мышление учителя: Личностные механизмы и понятийный аппарат / под ред. Ю.Н. Кулюткина, Г.С. Сухобской. М.: Педагогика, 1990. 104 с.

18. Туровский М.Б. Философские основания культурологии. М.: РОССПЭН, 1997. 440 с.

19. Кулюткин Ю.Н. Психологические особенности деятельности учителя // Мышление учителя. М.: Педагогика, 1990. С. 7-26.

20. Чарлтон Э. Основные принципы обучения здоровому образу жизни // Вопросы психологии. 1997. № 2. C. 3-13.

\title{
DEVELOPMENT OF PROSPECTIVE TEACHERS' READINESS TO FAMILIARIZE SCHOOLCHILDREN WITH THE VALUES OF PHYSICAL CULTURE WHILE STUDYING «PEDAGOGY»
}

(C) 2018

Borisov Alexandr Yakovlevich, candidate of pedagogical sciences, head of Physical Education Department Samara State University of Social Sciences and Education (Samara, Russian Federation)

Abstract. The paper considers the urgency of solving the problem connected with the development of prospective teachers' readiness to introduce schoolchildren to the values of physical culture in the context of preserving man as a social being and as a biological species. The values of physical culture are considered as a prerequisite for achieving a harmonious combination of bodily and spiritual principles in a person, as a condition for the full-fledged existence of a schoolboy, a student. Specific values of physical culture are singled out: «human motor activity», «human life», «health», «healthy lifestyle», «culture», «perseverance in achieving the goal», «moral perfection», «self-realization», etc. The author presents a structure of prospective teachers' readiness to familiarize schoolchildren with the values of physical culture, including cognitive motivational-value and activity components. Opportunities of «Pedagogy» for the development of prospective teachers' readiness to introduce students to the values of physical culture in theoreti$\mathrm{cal}$ and practical aspects are revealed. The theoretical aspect is the allocation of physical culture values at the scientific material level of «Pedagogy» sections (section «Introduction to pedagogical activity» - the values «human life», «culture», «persistence in achieving the goal», «self-determination», «self-organization» and others, section «Solving professional problems» - the values of «health», «healthy lifestyle», «perseverance in achieving the goal», «prestige of physical culture and sports», «freedom», «justice», etc.). The practical aspect is examples of development of prospective teachers' readiness to introduce schoolchildren to the values of physical culture during lecture and seminar classes in the sections «Solving professional problems» and «History of pedagogical thought in Russia and abroad». The conclusion is that the values mastered by the students will become the reference points for the education of the schoolchild who responsibly relate to their own health and the health of the surrounding people.

Keywords: readiness; student; future teacher; physical culture; value; value of physical culture; educational discipline; pedagogy; health; healthy way of life; pedagogical task; decision; reflection; orientation; initiation; schoolchild; formation; process.

\section{ТЕКСТУАЛЬНО-ДИАЛОГИЧЕСКИЙ ПОДХОД К ФОРМИРОВАНИЮ ГОТОВНОСТИ КУРСАНТОВ - БУДУЩИХ СОТРУДНИКОВ УГОЛОВНО-ИСПОЛНИТЕЛЬНОЙ СИСТЕМЫ К ГУМАНИСТИЧЕСКОМУ ВЗАИМОДЕЙСТВИЮ С ЧЕЛОВЕКОМ}

\section{(C) 2018}

Вдовин Сергей Александрович, кандидат педагогических наук, начальник юридического факультета Самарский юридический институт ФСИН России (2. Самара, Российская Федерация)

Аннотация. Статья посвящена проблеме подготовки будущего сотрудника уголовно-исполнительной системы, способного выстраивать отношения с окружающими людьми, в том числе и с людьми, преступившими закон и отбывающими наказание, на гуманистических основаниях. Актуальность гуманистического взаимодействия в условиях уголовно-исполнительной системы аргументируется с позиции идеи: «человек по своей природе, т.е. изначально, сущностно - добр». Предлагается определение гуманистического взаимодей- 
ствия курсанта - будущего сотрудника уголовно-исполнительной системы с человеком как особого типа отношений, фиксирующих понимание ценностей и поступков другого человека; актуализирующих нравственные, гуманистические ценности; рефлексирующих содержание собственных действий и поступков по отношению к другому; отражающих восприятие душевного мира другого человека. Текстуально-диалогический подход в образовании представляется как стратегия обучения, как образовательная технология, как собственно научный подход. Содержание текстуально-диалогического подхода к формированию готовности курсантов - будущих сотрудников уголовно-исполнительной системы к гуманистическому взаимодействию с человеком раскрывается через содержание понятий «текст» и «диалог». Обосновывается, что тексты, предъявляемые курсантам, в процессе формирования у них готовности, должны, во-первых, содержать такое знание, которое, выступая в значении гуманистических ценностей, позволяет курсантам осуществлять взаимодействие с другими людьми по критерию данных ценностей; во-вторых, отвечать критериям значимости, доступности и убедительности. Показывается, что в условиях диалога курсантами обретается личностный опыт гуманистического взаимодействия с другими людьми, позволяющий выбирать гуманистически ориентированный смысл диалогического взаимодействия с другим, находить адекватные для данной ситуации способов взаимодействия с другим человеком, осуществлять рефлексию своего отношения к другому.

Ключевые слова: готовность; курсант; будущий сотрудник уголовно-исполнительной системы; взаимодействие; гуманистическое взаимодействие; подход; текстуально-диалогический подход; текст; диалог; гуманизм; ценность; рефлексия; отношения; личностный опыт; формирование; человек.

Общество способно эффективно развиваться тогда, когда у него есть общая система нравственных ориентиров. Одним из таких нравственных ориентиров является гуманистическое взаимодействие человека с человеком, которое начинается с преодоления каждым из участников взаимодействия собственного эгоцентризма, попытки встать на позицию другого и, соответственно, попытаться эту позицию понять. Иными словами, начинается с установки на встречу со смыслом другого человека.

Нравственные ориентиры должны быть присущи всем без исключения членам общества независимо от социального положения, независимо от профессии. Однако есть сферы профессиональной деятельности, специфика которых затрудняет, а иногда и блокирует у специалиста вышеназванные ориентиры. Такой сферой является, например, уголовно-исполнительная система. Профессиональная деятельность сотрудника напрямую связана с людьми, совершившими различные преступные деяния, в том числе и отличающиеся жестокостью. Следует ли требовать от сотрудника уголовно-исполнительной системы следовать нравственным ориентирам во взаимодействии с такими людьми? На первый взгляд, нет: жестокость должна караться. Но тогда мы возвращаемся к тем временам, когда господствовало правило «око - за око, зуб - за зуб». Это путь не созидания, но разрушения: злом зла не исправишь, а только преумножишь. Конечно же, речь не идет о всепрощении преступников - нарушивший закон должен понести наказание. Речь идет о взаимодействии между сотрудниками уголовно-исполнительной системы и людьми, преступившими закон. От того, каким будет это взаимодействие, зависит, в том числе, встанет ли преступник на путь исправления.

Следовательно, сотрудник уголовно-исполнительной системы должен опираться на нравственные ориентиры в своей профессиональной деятельности. Заметим, что мы разделяем точку зрения Л.Е. Балашова, который утверждает, что «... человек по своей природе - т.е. изначально, сущностно - добр. Злой человек - это аномалия, исключение из правил, нравственно больной человек» $[1$, с. 56]. Если подходить ко всем людям с данной меркой, то можно настроиться на волну общения, сотрудничества и приязни. С таким отношением к людям, - пишет Л.Е. Балашов, - в душе укрепляется, усиливается гармония, процветает гармоническое ощущение жизни, вырабатывается гуманистическое убеждение, которое можно выразить афоризмом: «будем лучше думать о людях, и они на самом деле станут лучше» [1, c. 62].

Тем самым обозначается проблема: как подготовить сотрудника уголовно-исполнительной системы, следующего нравственным ориентирам в целом и осуществляющего гуманистическое взаимодействие с людьми, преступившими закон, в частности? Конечно же, важную роль здесь играет вуз, где обучается курсант - будущий сотрудник.

В рамках данной статьи мы обосновываем возможность реализации в образовательном процессе юридического вуза текстуально-диалогического подхода к формированию готовности курсантов - будущих сотрудников уголовно-исполнительной системы к гуманистическому взаимодействию с человеком.

Анализ научной литературы [2-10] позволил нам определить гуманистическое взаимодействие курсанта - будущего сотрудника уголовно-исполнительной системы с человеком как особый тип отношений, в которых зафиксировано понимание ценностей и поступков другого человека; актуализированы нравственные, гуманистические ценности; отрефлексировано содержание собственных действий и поступков по отношению к другому человеку; отражено восприятие душевного мира другого человека вплоть до «перенесения» себя в другого; и в которых (отношениях) реализуются нравственные качества.

Текстуально-диалогический подход рассматривается исследователями как стратегия обучения школьников (В.В. Сериков [11]), как образовательная технология (С.О. Бачурина [12]), как собственно научный подход к формированию готовности школьников к аксиологическому общению (М.А. Авдеева [13]), к формированию морального мышления будущего учителя (О.В. Ненашева [14]), к обучению иностранному языку в вузе (А.З. Ибатова, Л.В. Вдовиченко [15]).

Суть текстуально-диалогического подхода, по утверждению В.В. Серикова, заключается в том, что изучаемый материал предъявляется ученику (курcaнmy. - C.B.) как текст, к которому ученик (курсант. - C.B.) должен выразить свое субъективное отношение, вступив в своеобразный диалог с его автором [11, с. 190-191]. 
Мы полагаем, что в контексте решения проблемы формирования готовности будущих сотрудников уголовно-исполнительной системы к гуманистическому взаимодействию с человеком сущность данного подхода может быть расширена в том плане, что диалог понимается не только как диалог курсанта с автором того или иного текста, но и как диалог между людьми, а также как диалог с самим собой.

Содержание текстуально-диалогического подхода определяется понятиями «текст» и «диалог».

Текст - это, прежде всего, носитель информации. Информация, составляя предметное содержание текста, в то же время не существует сама по себе и для себя. Информация предназначена для людей. Такая предназначенность и определяет функциональную направленность текста. Мы ведем речь об информации, предназначенной для будущих сотрудников уголовно-исполнительной системы, но не о всей учебной информации, а о той, что несет в себе гуманистическую составляющую. Эта информация содержит в себе знание о морали, о нравственности, о ценностях, о гуманизме, о способах и средствах осуществления гуманистического взаимодействия с другим человеком. Экстраполируя идеи В.П. Бездухова о смысловой составляющей знания, которая наполняет информацию учителя смыслом и определяет способ его бытийствования в педагогическом пространстве [16, с. 82], скажем, что смысловая составляющая знания о морали, о нравственности, о ценностях, о гуманизме обосновывает выбор курсантом способов осуществления взаимодействия с другими людьми. Результаты такого взаимодействия осмысливаются будущим сотрудником уголовноисполнительной системы в контексте идей гуманизма, соотносятся с этими идеями. Осмысление позволяет выявить соответствие или несоответствие взаимодействия курсанта с другим человеком критериям гуманистического взаимодействия. И только после этого в содержание взаимодействия, в способы его осуществления вносятся коррективы, направленные на гуманизацию взаимодействия.

Реализация текстуально-диалогического подхода к формированию готовности будущих сотрудников уголовно-исполнительной системы к гуманистическому взаимодействию с человеком, в первой его (подхода) части (текст), требует вычленения в учебных текстах по изучаемым курсантами в вузе дисциплинам того знания, которое, выступая в значении гуманистических ценностей, позволяет будущим сотрудникам уголовно-исполнительной системы осуществлять взаимодействие с другими людьми по критерию названных ценностей.

Исходный принцип, определяющий внутреннюю активность личности в процессе восприятия учебного текста, в формулировке Ю.Н. Кулюткина выглядит следующим образом: «структура изложения содержания, заключенного в тексте, должна соответствовать психологической структуре познавательной деятельности человека; восприятие текста должно строиться как процесс решения определенной познавательной проблемы» [17, с. 308-309]. В контексте поднимаемой в статье проблемы возможна реализация данного принципа во второй его части. Это означает, что восприятие учебного текста курсантами выстраивается как процесс решения конкретной задачи - задачи определения средств и способов осуществления гуманистического взаимодействия с другими людьми.

Естественно, что далеко не вся информация, отражаемая в учебных текстах, содержит в себе знание о гуманизме, нравственности, морали, ценностях, взаимодействии. Задача преподавателя вуза, который формирует готовность курсантов к гуманистическому взаимодействию с человеком, состоит в том, чтобы в содержании учебных текстов по возможности вычленить вышеозначенную информацию, а также в рамках конкретных дисциплин подготовить тексты, содержащие знание о морали, о ценностях, о гуманизме, об особенностях взаимодействия между людьми.

Работа будущих сотрудников уголовно-исполнительной системы с информацией, содержащей данное знание, возможна, с нашей точки зрения, в процессе специально создаваемой преподавателем вуза гуманитарной ситуации в обучении. Гуманитарная ситуация обучения, подчеркивает В.В. Сериков, «состоит в возможности: проживания и рефлексии отношения к "своему" и "чужому" "тексту"; взаимодействия (сотрудничества, со-бытия) с "другим", осуществляющим себя в тексте; осознавания (самоосознавания) своего индивидуального "языка" в процессе культурной коммуникации; разрешения противоречий, связанных с возможностями понимания других субъективных "языков"» [11, с. 192].

Мы полагаем, что предлагаемое В.В. Сериковым содержание гуманитарной ситуации обучения может быть конкретизировано в рамках текстуально-диалогического подхода к формированию готовности курсанта - будущего сотрудника уголовно-исполнительной системы к гуманистическому взаимодействию с человеком следующим образом: курсант, производя рефлексию текста с точки зрения содержащегося в нем знания о морали, о нравственности, о ценностях, о гуманизме, осуществляет опосредованное взаимодействие с другим человеком - автором текста. Опосредованно взаимодействуя с автором текста, курсант, разрешая возникающие в понимании субъективного «языка» текста противоречия, руководствуется ценностями добра, блага, взаимопонимания, гуманизма и т.д.

Рефлексия текста как обязательная составляющая гуманитарной ситуации в обучении соотносится со взглядами Ю.Н. Кулюткина на восприятие текста: «По существу, восприятие текста - это процесс рефлексивный, процесс отражения учеником того, что было отражено автором текста, процесс понимания авторского понимания ("со-понимание"), процесс оценивания авторской оценки ("со-оценивание"), процесс оперирования в соответствии со способами, предложенными автором ("со-оперирование")» [17, с. 309].

Мы полагаем, что тексты, предъявляемые курсантам, в процессе формирования у них готовности к гуманистическому взаимодействию с человеком, должны отвечать таким критериям, как значимость, доступность и убедительность. Критерии эти выделяются нами вслед за Ю.Н. Кулюткиным, который рассматривает их как критерии, определяющие эффективность воздействия текста на личность.

Ю.Н. Кулюткин доказывает, что текст будет активно восприниматься человеком в том случае, если 
его содержание будет для личности в том или ином отношении значимым, то есть отвечать определенным ее потребностям и запросам [17, с. 309]. В контексте решения задачи формирования готовности будущих сотрудников уголовно-исполнительной системы к гуманистическому взаимодействию с человеком это означает, что предъявляемый курсантам текст должен, во-первых, апеллировать к их потребности в осуществлении взаимодействия с другими людьми, во-вторых, представлять интерес в плане будущей профессиональной деятельности будущих сотрудников уголовно-исполнительной системы. Иными словами, в том или ином объеме содержать информацию о том, как эффективно строить взаимодействие с другим человеком в русле такой деятельности.

Другим критерием эффективности воздействия текста на личность, по мнению Ю.Н. Кулюткина, является его доступность. Ученый пишет: «Текст будет активно восприниматься в том случае, если он будет доступным для понимания, то есть соответствовать познавательным силам и возможностям человека, который воспринимает данный текст» [17, с. 309310]. Относительно работы с курсантами это означает, что содержание предлагаемых им текстов должно максимально приближаться к личностному опыту будущих сотрудников уголовно-исполнительной системы, что язык и терминология текстов должны быть понятны курсантам.

Ю.Н. Кулюткин считает, что содержание текста будет активно восприниматься при условии, если человек, которому оно адресовано, внутренне согласен с аргументами и выводами, заключенными в данном тексте $[17$, с. 310$]$. Данный критерий ученый обозначил как убедительность текста. При формировании готовности курсантов к гуманистическому взаимодействию с человеком убедительность заключается в обоснованности выводов, сделанных в тексте, что достигается в том числе и за счет приведения конкретных примеров из практической деятельности сотрудника уголовно-исполнительной системы, так как последняя является сферой будущей профессиональной деятельности курсантов.

Важным условием, влияющим на овладение знанием, содержащимся в информации, образующей текст, является понимание содержания текста.

Понимание как процесс, относящийся к процессам коммуникации между людьми, имеет диалогическую природу. Это всегда понимание содержания, которое передается человеку от другого человека. Понять можно только то, что имеет значение и смысл. Именно смысловое значение, - подчеркивает Ю.Н. Кулюткин, - является главной единицей, лежащей в основе понимания речи, понимания текста $[17$, c. 312].

Обращаясь к пониманию, мы переходим к раскрытию второго понятия, образующего текстуальнодиалогический подход, а именно к диалогу.

Проведенный Ю.Н. Кулюткиным анализ исследований, осуществленных в рамках философии, культурологии, психологии, педагогики, позволил ученому сделать вывод о том, что диалогичность есть центральная характеристика гуманитарно-ориентированного (гуманистического. - C.B.) взаимодействия между людьми (индивидами, группами, общностями), что она есть универсальный способ суще- ствования культуры и человека в культуре, внутренний механизм развития человеческого мышления [17, с. 289]. Диалог, подчеркивает ученый, способствует выработке установки не только на то, чтобы учитывать мнение другого, но и на то, чтобы находить точки соприкосновения между мнениями участников диалога, открывать в них нечто общее, входить в единое смысловое поле, возникающее в многоголосице дискуссий и обсуждений [17, с. 307].

В основаниях концепции диалогического понимания, согласно Ю.В. Сенько, находится понятие «Другой», позволяющее проявить суть диалогических взаимоотношений, неслиянность позиций участников диалога. Из этого вытекает признание равноправности и равноценности Другого как субъекта процесса обучения [18, с. 130] (и добавим: взаимодействия. - C.B.).

Как пишет М.А. Петренко, «в ситуации диалога два человека образуют некое общее психологическое пространство - время совместного бытия со-бытия, в котором воздействие и взаимодействие в традиционном смысле слова превращаются в сложноопосредованные взаимовлияния, создающие психологические единство субъектов. В этом событийном единстве создаются условия для взаимораскрытия и взаиморазвития, закладываются предпосылки для самовоздействия и развертываются процессы саморазвития» $[19$, c. 245$]$.

В условиях диалога (в том смысле, как его понимают Ю.Н. Кулюткин, Ю.В. Сенько, М.А. Петренко) курсантами обретается личностный опыт гуманистического взаимодействия с другим человеком. Экстраполируя идеи С.В. Беловой о гуманитарном личностном опыте учащихся [20, с. 18-37], мы полагаем, что личностный опыт гуманистического взаимодействия будущего сотрудника уголовно-исполнительной системы с другим человеком предполагает, вопервых, выбор смысла диалогического взаимодействия с другим. При этом это должен быть именно гуманистически ориентированный смысл, так как смыслом взаимодействия может быть и извлечение личной выгоды. Во-вторых, поиск адекватных для данной ситуации способов взаимодействия с другим. Способы эти, особенно если это касается профессиональной деятельности сотрудника уголовно-исполнительной системы, должны полностью исключить агрессию в любых ее формах. В-третьих, рефлексию своего отношения к другому человеку. Осуществляя такую рефлексию, курсант выявляет, что привлекает и что раздражает его в другом человеке, осмысливает положительное и отрицательное в другом и на основании этого осмысления определяет собственную диалогическую позицию по отношению к другому человеку. Имеется в виду, что если в силу профессиональной деятельности курсант - будущий сотрудник уголовно-исполнительной системы сталкивается с человеком, в котором отрицательные качества явно преобладают, то и в этом случае диалогическая позиция курсанта не будет основываться на грубости и агрессии.

Наиболее полно вышеобозначенный опыт может реализоваться в рамках гуманистически-ориентированного диалога. По утверждению С.П. Ивановой, высшая цель понимания в процессе позитивного гуманистически-ориентированного диалога: понять другого человека как истину (понять тот единствен- 
ный, только ему принадлежащий путь, который ведет к самореализации) и оказать ему помощь, поддержку в решении экзистенциональных задач овладения своим бытием (в состоянии духовного кризиca, разочарования, неудачи) или сообщить энергию успеха [21, с. 54]. Заметим, что состояния духовного кризиса, разочарования, неудачи и подобные им состояния характерны для большинства людей, попавших в сферу профессиональной деятельности сотрудника уголовно-исполнительной системы.

В концепцию гуманистически-ориентированного диалога вписывается структура диалога, предлагаемая М.А. Петренко: обращение как восприятие другого в его идентичности; вопрошание как видение ценности другого, забота о его существовании; слушание как принятие другого [19, с. 245].

Итак, реализация текстуально-диалогического подхода к формированию готовности будущих сотрудников уголовно-исполнительной системы к гуманистическому взаимодействию с человеком предполагает, во-первых, вычленение в учебных текстах по изучаемым курсантами дисциплинам такого знания о принимающих значение ценностей понятиях морали, о ценностях, которое обосновывает выбор курсантом способов гуманистического взаимодействия; во-вторых, создание на учебных занятиях и в период производственной практики таких ситуаций диалогического общения, содержание которых позволяет курсантам проявлять эмпатию, толерантность, конструктивность, сотрудничество, осуществлять гуманистическое взаимодействие с человеком и рефлексию результатов такого взаимодействия в моделируемых в учебном процессе и в спонтанно возникающих в период производственной практики ситуациях взаимодействия с людьми.

\section{Список литературы:}

1. Балашов Л.Е. Этика: учебное пособие. М.: Дашков и К, 2004. 176 с.

2. Бездухов А.В. Сущность нравственно-педагогического взаимодействия учителя и учащихся // Образование и саморазвитие. 2011. № 1 (23). С. 124 129.

3. Борытко Н.M. В пространстве воспитательной деятельности. Волгоград: Перемена, 2001. 181 с.

4. Иванова С.П. Учитель XXI века: ноопсихологический подход к анализу профессионально-личностной готовности к педагогической деятельности. Псков: ПГПИ им. С.М. Кирова, 2002. 228 с.

5. Коротаева Е.В. Основы педагогических взаимодействий. Екатеринбург: УрГПУ, 2000. 143 с.

6. Радионова Н.Ф. Взаимодействие педагогов и старших школьников. Л.: ЛГПИ им. А.И. Герцена, 1989. $84 \mathrm{c}$.

\section{TEXTUAL-DIALOGICAL APPROACH TO THE DEVELOPMENT OF HUMANISTIC PERSON INTERACTION ABILITY OF CADETS - PROSPECTIVE PENAL-EXECUTIVE SYSTEM EMPLOYEES (C) 2018

\author{
Vdovin Sergey Alexandrovich, candidate of pedagogical sciences, dean of Law Faculty
} Samara Law Institute of the Federal Penitentiary Service of Russia (Samara, Russian Federation)}

Abstract. The article is devoted to the problem of training a future employee of the penal system, which is able to build relationships with surrounding people, including people who have transgressed the law and who serve punishment on humanistic grounds. The urgency of humanistic interaction in the conditions of the criminal executive system is argued from the position of the idea: «a person by nature - i.e. initially, essentially - good». The author proposes a definition of a humanistic interaction between a cadet and a future employee of the criminal executive system
.: Логос, 2004. 272 c.

8. Ситаров В.А., Маралов В.Г. Психология и пе-

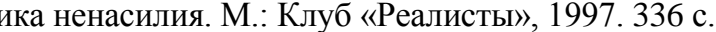

Педагогическое общество России, 2002. 224 с.

ствие преподавателей и студентов в процессе адаптации студентов // Педагогический опыт: теория, методика, практика. 2016. № 1 (6). С. 137-140.

11. Сериков В.В. Обучение как вид педагогичедеятельности. М.: Академия, 2008. 256 с. виях повышения квалификации к реализации текстуИзвестия Волгоградского государственного педаго.

дход к формированию готовности школьников к аксиологическому общению в школе // Поволжский педагогический вестник. 2016. № 1 (10). С. 33-37.

дход к формированию морального мышления студента - будущего учителя // Известия Самарского научного центра Российской академии наук. Социальные, гуманитарные, медико-биологические науки. 015. Т. 17. № 1-4. С. 845-849.

текстуально-диалогического подхода в обучении иностранному языку в вузе // Глобальный научный

люткин Ю.Н., Бездухов В.П. Ценностные ориентиры и когнитивные структуры в деятельности учителя. Самара: СГПУ, 2002. С. 67-173.

17. Кулюткин Ю.Н. Диалог как предмет педагоЦенностные ориентиры и когнитивные структуры в деятельности учителя. Самара: СГПУ, 2002. С. 274-329.

ческого образования. М.: Академия, 2000. 240 с.

19. Петренко М.А. Генезис диалогического подхода в науке и образовании // Известия Российского государственного педагогического университета

20. Белова С.В. Педагогика диалога: теория и практика построения гуманитарного образования. АПКиППРО, 2006. $380 \mathrm{c}$ гический подход к анализу профессионально-личностной готовности к педагогической деятельности. Псков: ПГПИ им. С.М. Кирова, 2002. 228 с. ально-диалогической образовательной технологии // отенциал. 2015. № 11 (56). С. 22-24. 
with a person as a special type of relationship that fixes the understanding of the values and actions of another person; actualizing moral, humanistic values; reflecting the content of their own actions and actions in relation to the other; reflecting the perception of the spiritual world of another person. The textual-dialogical approach in education is presented as a learning strategy, as an educational technology, as a scientific approach. The content of the textualdialogical approach to the development of cadets-future employees of the penal-executive system ability for humanistic interaction with a person is revealed through the content of the concepts «text» and «dialogue». It is justified that the texts presented to cadets while developing their ability should, firstly, contain such knowledge, which, speaking in the meaning of humanistic values, allows students to interact with other people on the basis of these values; secondly, to meet the criteria of significance, accessibility and credibility. It is shown that, in the context of dialogues, cadets acquire personal experience of humanistic interaction with other people, which allows them to choose a humanistic oriented sense of dialogical interaction with another, find ways of interaction with another person that are adequate for this situation, and reflect their attitude to another.

Keywords: readiness; cadet; future employee of penal system; interaction; humanistic interaction; approach; textual dialogical approach; text; dialogue; humanism; value; reflection; relationships; personal experience; development; person.

УДК 376.37

Статья поступила в редакцию 04.10.2017

\section{ОСОБЕННОСТИ КОРРЕКЦИОННОЙ РАБОТЫ ПРИ НАРУШЕНИЯХ ВОСПРИЯТИЯ РЕЧИ НА СЛУХ}

(C) 2018

Визель Татьяна Григорьевна, доктор психологических наук, ведущий научный сотрудник кафедры специального (дефектологического) образования Московский институт психоанализа (г. Москва, Российская Федераџия)

Аннотация. В настоящей статье затронута проблема нарушений восприятия речи на слух (речевой слуховой агнозии). Обсуждается их место в ряду дефектов речи, имеющих специфическую иерархию - от тугоухости до нарушения понимания речи на слух.

Подчеркивается, что у детей механизмы, по которым имеет место речевая слуховая агнозия, могут иметь истоки в неполноценности процессов восприятия неречевых шумов. Особое место уделяется вопросам дифференциальной диагностики различных нарушений слухового восприятия, а также тому, что отсутствие собственной артикулированной речи у ребенка прямо зависит от того, насколько хорошо он воспринимает речь окружающих. Таким образом, утверждается, что артикуляционная апраксия у детей не первична. Следовательно, это необходимо учитывать в построении программ коррекционного обучения. Оно должно быть дифференцировано в зависимости от конкретного вида нарушения слуховой функции и содержать приемы сенсорной интеграции, рассчитанной на сохранные анализаторные системы. За счет применения специальных коррекционных методик симптомы речевой слуховой агнозии могут быть устранены или в значительной мере ослаблены (в отличие от первичной тугоухости).

Ключевые слова: нарушение восприятия речи на слух; слуховая агнозия; сенсорная алалия; этапы развития слухового восприятия; мозговые механизмы; межзональные связи; проводящие пути; компенсация; коррекционное обучение; обходные методы; сохранные анализаторные системы; сенсорная интеграция.

Решение предложить вниманию специалистов данную статью продиктовано опытом общения с теми из них, кто работает в области патологии речи. Выяснилось, что феномену речевой слуховой агнозии (РчСлАгн), а также его отличиям от тугоухости и нарушений понимания слов на слух на практике далеко не всеми придается должное значение.

Литература в рамках дефектологии, посвященная дифференциальным различиям в нарушении слухового восприятия, ограниченна, если не считать область сурдологии, где идет речь о глухих и тугоухих детях. Более обстоятельно феномен слуховой агнозии раскрывается в нейропсихологии (А.Р. Лурия [1], Е.Д. Хомская [2], Л.С. Цветкова [3], Т.Г. Визель [4; 5] и др.). Однако эта литература не всегда рекомендуется для изучения дефектологам и отоларингологам.

Обобщим коротко сложившиеся в нейропсихологии представления о структуре восприятия речи на слух. Согласно им, каждый высший уровень данного процесса надстраивается над предыдущим и в таком порядке приобретается в онтогенезе. Височная (слуховая) кора обоих полушарий включает первичные, вторичные и третичные поля, выполняющие различ- ные по степени сложности функции. Наиболее элементарные первичные (I) расположены в ядре зоны, вторичные (II), функционально более сложные, ближе к периферии; наиболее сложно функционирующие третичные (III) - на периферии зоны.

Первичные поля слуховой коры обеспечивают слышание (уровень физического слуха); вторичные дифференциацию разных звучаний, различение их соответственно источнику звука (уровень слухового гнозиса); третичные поля - понимание значений слышимого (смысловой уровень).

Каждое из иерархически соотносимых полей мозга может оказаться работающим неполноценно. На уровне первичных полей это проявляется в виде нарушений физического слуха (глухота, тугоухость), на уровне вторичных полей - в виде слуховой агнозии. Если неполноценны поля правого полушария, то нарушения слухового восприятия выступают в виде неречевой слуховой агнозии (НрчСлАгн - неразличения шумов окружающего мира), а если неполноценны вторичные поля левого полушария, то в виде речевой слуховой агнозии (РчСлАгн - неразличения звукового состава воспринимаемой на слух речи). 